\title{
Ligamentum Flavum Cyst - A Rare Cause of Lumbar Canal Stenosis: A Case Report with Review of Literature
}

\author{
Sanyam Jain, Pankaj Jindal, Puneet Girdhar, Bhupendra Bharti, Rajesh Verma
}

Department of Orthopaedics and Spine, BL Kapur Hospital, Delhi, India

Corresponding Author:

Dr Sanyam Jain, MBBS, M.S.ORTHO Department of Orthopaedics and Spine, BL Kapur Hospital, Delhi, India Room no 32, opd 1, ground floor, BLK hospital, Pusa road, New delhi 110005

Tel: +9727776564

E-mail: jainsanyam933@gmail.com

Received: November 02, 2020

Revised: February 09, 2021

Accepted: March 24, 2021

\begin{abstract}
Lumbar spinal stenosis is most common entity coming to spine out-patient department which may present with complaint of back pain with lower limbs neurogenic claudication, caused by degenerative disc conditions or to facet joint hypertrophy or ligamentum flavum thickening. We represent a case report of a patient suffering from low back pain with worsening neurogenic claudication. Imaging showing a cystic lesion at L3-4 spinal level with no lysthesis pinching the traversing nerve root who undervent minimal invasive tubular transforaminal lumbar interbody fusion. Intraoperatively, a cystic mass originating from ligament flavum with yellow jelly fluid adherent to dura and no communication with subarachnoid space or facet joint was found. Histologically, these cysts represent a distinct entity different from synovial cysts in terms of devoid of epethelial lining. To differentiate in cyst outlines and origin is very helpful in preoperative planning as even complete removal of ligamentum flavum cyst does not damage the facet joint and no fixation is required in these cases as compared to facetal cyst which represents instability and fixation is mandatory.
\end{abstract}

Key Words: Ligamentum flavum (LF), Cystic lesion, Synovial lining

\section{INTRODUCTION}

Lumbar spinal stenosis is most common entity coming to spine out-patient department which may present with complaint of back pain with lower limbs neurogenic claudication, caused by degenerative disc conditions or due to facet joint hypertrophy or ligamentum flavum thickening. Less common etiologies include cystic lesions like synovial cysts ${ }^{1)}$, ganglion pseudocysts ${ }^{2)}$, dermoid cysts or parasitic cysts ${ }^{3}$, or other intraspinal extradural masses like haematoma or metastatic lesions. Our case report mention the case of ligamentum flavum cyst with lumbar canal stenosis operated minimally invasive surgery and technical difficulties faced during surgery.

\section{CASE RRPORT}

\section{Case 1}

A 57-year female patient presented with low back pain with worsening neurogenic claudication since 1-year with right lower limb pain. Walking distance continued decreasing since last 1 year. There was no history of trauma, fever, weight loss or any other constitutional symptoms. Clinical examination revealed moderate weakness (grade 3/5) in extension of the right great toe. Otherwise, motor examination in all other muscle groups and sensory examination of all modalities was with in normal limits. Plain radiographs of the lumbosacral spine showed degenerative changes like reduced height but no lysthesis at L3-4 level in fle- xion and extension lateral views. Blood parameters showed normal white cell count (WCC), erythrocyte sedimentation rate (ESR) and C-reactive protein (CRP). Magnetic Resonance Imaging (MRI) scan showed a cystic lesion, T1 hypointense and T2 hyperintense with moderate rim enhancement in between dural sac and ligamentum flavum at L3/4 level, compressing and displacing the thecal sac and pinching the traversing nerve root. The patient was treated conservatively initially with analgesics and physiotherapy but failed to alleviate the patient's symptoms. After proper counselling and adequate trail of conservative management, minimal invasive tubular posterior decompression and stabilization with transforaminal interbody fusion at L3-L4 level was performed. Intraoperatively, a cyst was noted in the epidural space attached to ligamentum flavum at L3-4 level. 


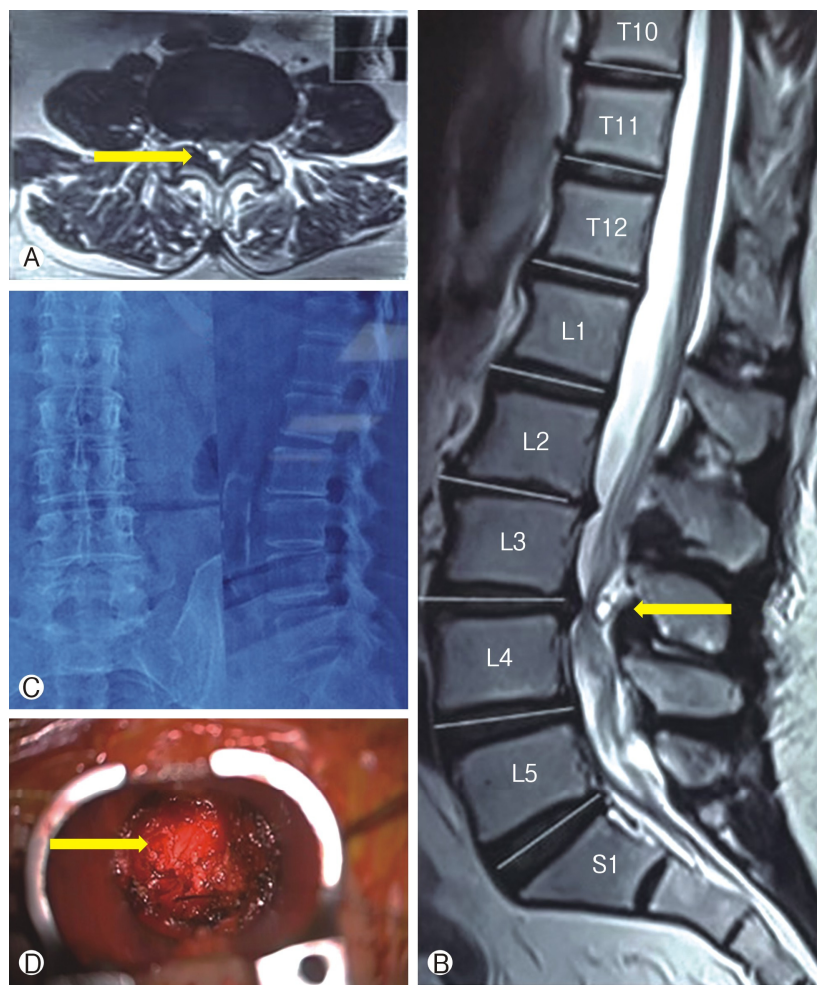

Figure 1. Demostrates (A) Preoperative axial scan MRI (B) Sagital scan MRI scans (C) Preoperative $x$-ray image (D) Intraoperative microscopic image demostrating cystic lesion in ligamentum flavum.
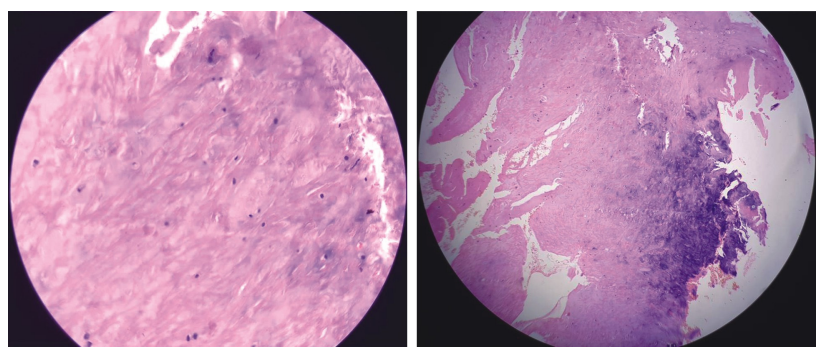

Figure 2. Microscopic histology image of the cyst showing proliferation of capillaries with fibro-cartilageneous wall. Cyst lining is devoid of epithelium.

\section{Surgical Procedure}

The patient was placed under general anesthesia in the prone position. Tube was docked at L3-L4 right side facet joint, then inferior facetectomy and laminotomy was done, thus exposing ligamentum flavum. We found moderate thickening of the capsule of the apophyseal joint and thickened ligamentum flavum. We found that cystic mass was originated from ligament flavum and contained yellow fluid which was adherent to dura and there was no communication with the subarachnoid space or facet joint. Then, it was freed from all around with the help of nerve hook. The right $L 4$ nerve root was compressed and pushed laterally by the cyst, and after removal of cyst, nerve root was completely freed. No CSF leakage occurred during removal.

The dorsal side of the cyst extended in a space in the $L 3 / 4$ interspinous space, whereas the ventral wall was densely adhered to the dura. The thecal sac was decompressed by excising the cyst wall and drainage of clear fluid inside.

Further over the top decompression was done and decompression achieved. Cage inserted after disc space prepared and standard transforaminal interbody fusion was acheived. Post-operatively, mobilization out of bed allowed immediately on next post operative day. On regular follow ups, the patient showed significant relief from the spinal claudication symptoms. Histological examination of the resected specimen demonstrated fibrous connective tissue devoid of lining epithelium.

\section{DISCUSSION}

Identifying and differentiating the origin of the cystic lesions preoperatively have important implications to our surgical planning in terms of fixation and decompression or decompression alone and the extent of surgical exploration to achieve complete cyst resection to minimize the chance of recurrence.

Ligamentum flavum cyst, first reported by Moiel et al. in 1967 is rare cause of spinal stenosis mentioned in literature ${ }^{3-8)}$. Kao et al. ${ }^{9)}$ and Rhoton et al. ${ }^{10)}$ first used the term "juxtafacet cyst" in 1974 and dividing them into synovial cyst arising from facet joint with a synovial lining and ganglionic cysts arising from or grow into ligamentum flava adjacent to facet joint without any synovial lining. Chimento et $\mathrm{al}^{1{ }^{11)}}$ in 1995 reported that ganglion cysts includes cysts of the ligamentum flavum and posterior longitudinal ligament.

The anatomic disposition, histologic characteristics, and biomechanical properties of the ligamentum flavum indicate that it is markedly different from other spinal ligaments ${ }^{26}$. The ligamentum flavum is a well-defined elastic structure composed of $80 \%$ elastic and $20 \%$ collagen fibers ${ }^{27)}$.

The pathogenesis of ligamentum flavum cysts remains unknown ${ }^{12-14)}$ reflecting mainly degeneration rather than trauma however, hypertrophy, degeneration and fibrosis of the ligamentum flavum are frequently present and likely to be sequelae of localized minor spinal trauma ${ }^{15,18)}$. The ligamentum flavum cyst is regarded to be associated with microtrauma due to increased motion at a particular motion segment or segmental instability and local stress associated with degeneration at the level of occurrence ${ }^{16,17,28)}$. Change in proteoglycans, loss of elastic fibers, and increase in collagen tissue and chondroid metaplasia due to mechanical stress have also been described ${ }^{19)}$.

Additionally and closely related to age, amyloid can accumulate within the ligamentum flavum ${ }^{20)}$ and might be associated with systemic amyloidosis ${ }^{21)}$.

Similarly, age-related calcification of the ligamentum flavum can occur $^{22)}$. A diffuse form of calcification contributing to the loss of elasticity and the thickening and a focal form of calcified material accumulation as well as granulomatous inflammation and tophaceous depositions of calcium pyrophosphate crystals can occur. These depositions have been ascribed to decreasing 
cellularity and result in diminished calcification inhibiting factor production by fibroblastic-like cells ${ }^{23}$. The tophaceous type of lesion seems to be closely related to previous degeneration of the affected ligament by minor trauma predisposing to calcium deposition. Activity of proteolytic enzymes within the ligament, produced by neutrophils localizing to calcified nodules, has been found ${ }^{24)}$.

Patients with ligamentum flavum cysts are also noted to have co-existence of facet joint degeneration, and incidence of degenerative spondylolisthesis varies between 42 and $65 \%{ }^{25}$.

Most of the reported ligamentum flavum cysts in the literature were located laterally within the spinal canal similar in our case. Cervical cysts are preferentially located in the cervicothoracic junction ${ }^{31,29)}$. No reports have described the appearance of these cysts in any region other than the mobile spine. The T2-10 vertebrae mainly act with the ribs to form the thorax and are not generally considered to be part of the mobile spine.

Ligamentum flavum cysts in the lumbar spine occur commonly at L4-5 level because this level is the most mobile segment. The frequency at lumbar spine of ligamentum flavum cyst was as follows: L4-5 (56\%), L5-S1 (23\%), L3-4 (20\%), L2-3 (1\%) level.

Magnetic resonance imaging provides the best images ${ }^{30}$ : on T1weighted images, the cysts have a variable signal, and on T2-weighted images, the cysts have a high-intensity signal. Differential diagnosis of imaging studies between ligamentum flavum cysts and synovial cysts is helpful, as the latter are more difficult to resect, requiring exploration of the facet joint. Magnetic resonance imaging in case of synovial cysts, reveals demonstrable communication with the facet joint. CT scan imaging is helpful to diagnose the flaval cyst as it shows absence of enhancement of the cyst wall and surrounding calcified rim as compared to synovial cystic lesion with enhancement of the synovial cyst wall with calcified rim. In our case, magnetic resonance imaging revealed at L3-L4 level a right-sided voluminous epidural cystic lesion, $10 \mathrm{~mm}$ in diameter, which was hypointense on T1-weighted images and hyperintense on T2-weighted images.

Wildi et al. ${ }^{31)}$ reported recurrence of the cyst in the remaining ligamentum flavum in two patients 1 year after surgery. While nearly $95 \%$ of all operated cysts can be removed entirely, a major reported intraoperative difficulty lies in the presence of adhesions to the dural wall, which is the main causative factor of incomplete resection. Complete removal of these cystic lesions generally has excellent results ${ }^{30-33)}$.

Kim $\mathrm{H}$ et al. ${ }^{34)}$ clearly defined the different type of extradural cysts based on anatomic location and based on pathology.

Take home message-Ligamentum flavum cyst represent a rare cause of nerve root compression or spinal stenosis. Proper preoperative knowledge and planning with various imaging studies helps in differentiating the various epidural cystic lesions to define the treatment plan and to avoid fixation as removal of the ligamentum flavum cyst does not injured the facet and no fixation is required as compared to facetal cyst which represents instability and fixation is mandatory.

\section{CONFLICT OF INTEREST}

No potential conflict of interest relevant to this article.

\section{REFERENCES}

1. Onofrio BM, Mih AD: Synovial cysts of the spine. Neurosurgery 22(4):642-647, 1988

2. Ogawa Y, Kumano K, Hirabayashi S, Aota Y: A ganglion cyst in the lumbar spinal canal: A case report. Spine 17(11):1429-1431, 1994

3. Baker JK, Hanson GW: Cyst of the ligamentum flavum. Spine 19: 1092-1094, 1992

4. Barlocher CB, Seiler RW: Vertebral erosion and a ligamentum flavum cyst. Case illustration. J Neurosurg 93(2 Suppl):335, 2000

5. Cakir E, Kuzeyli K, Usul H, Peksoyulu B, Yazar U, Reis A, Karaarslan G: Ligamentum flavum cyst. J Clin Neurosci 11:67-69, 2004

6. Savitz MH, Sachdev VP: Cyst of the ligamentum flavum: Report of six cases. Neurosurgery 30:461-462, 1992

7. Terada H, Yokoyama Y, Kamata N, Hozumi T, Kondo T: Cyst of the ligamentum flavum. Neuroradiology 43:49-51, 2001

8. Vernet O, Frankhauser H, Schnyder P, et al.: Cyst of the ligamentum flavum: Report of six cases. Neurosurgery 29:277-283, 1991

9. Kao CC, Winkler SS, Turner J: Synovial cyst of spinal facet. J Neurosurgery 41:372-376, 1974

10. Rhoton A, Kao C, Uihlein A: Extradural ganglion cyst. Handbook of Clinical Neurology North-Holland Pub Co, Amsterdam: North Holland: pp605-609, 1976

11. Chimento GF, Ricciardi JE, Whitecloud $3^{\text {rd }} \mathrm{T}$ : Intraspinal extradural ganglion cyst. J Spinal Disord 8:82, 1995

12. DiMaio S, Marmor E, Albrecht S, Mohr G: Ligamentum flavum cysts causing incapacitating lumbar spinal stenosis. Can J Neurol Sci 32(2):237-242, 2005

13. Ayberk G, Ozveren F, Gok B, Yazgan A, Tosun H, Seckin Z, Altundal N: Lumbar synovial cysts: Experience with nine cases. Neurologia Medico Chirurgica 48(7):298-303, 2008

14. Baker JK, Hanson GW: Cyst of the ligamentum flavum. Spine (Phila Pa 1976) 19(9):1092-1094, 1994

15. Dockerty MB, Love JG: Thickening and fibrosis (so-called hypertrophy) of the ligamentum flavum: A pathologic study of 50 cases. Mayo Clin Proc 15:161-166, 1940

16. Sabo RA, Tracy PT, Weinger JM: A series of 60 juxtafacet cysts: Clinical presentation, the role of spinal instability, and treatment. J Neurosurg 85(4):560-565, 1996

17. Kao CC, Uihlein A, Bickel WH, Soule EH: Lumbar intraspinal extradural ganglion cyst. J Neurosurg 29(2):168-172, 1968

18. Abdullah AF, Chambers RW, Daut DP: Lumbar nerve root compression by synovial cysts of the ligamentum flavum: Report of four cases. J Neurosurg 60(3):617-620, 1984

19. Okada A, Harata S, Takeda Y, et al.: Age-related change in proteoglycans of human ligamentum flavum. Spine 18:2261-2266, 1993

20. Savitz MH, Sachdev VP: Cyst of the ligamentum flavum: Report of six cases. Neurosurgery 30:461-462, 1992

21. Roche PH, Figarella-Branger D, Malca S, et al.: Lumbar canal stenosis caused by amyloidosis of the yellow ligament. Neurochirurgi 45:91-97, 1999

22. Schrader PK, Grob D, Rahn BA, et al.: Histology of the ligamen- 
tum flavum in patients with degenerative lumbar spinal stenosis. Eur Spine J 8:323-328, 1999

23. Maruta $\mathrm{K}$, Ichimura $\mathrm{K}$, Matsui $\mathrm{H}$, et al.: Calcification inhibitors in human ligamentum flavum. J Orthop Res 11:92-103, 1993

24. DiMario S, Marmor E, Albrecht S, Mohr G: Ligamentum flavum cysts causing incapacitating lumbar spinal stenosis. Can J Neurol Sci 32:237-242, 2005

25. Apostolaki E, Davies EM, Evans N, Cassar-Pullicino VN: MR imaging of lumbar facet joint synovial cysts. Eur Radiol 10(4): 615-623, 2000

26. Fuertes DV, Liguoro D, Rivel J: Morphologic and histologic study of the ligamentum flavum in the thoraco-lumbar region. Surg Radiol Anat 20:171-176, 1998

27. Yahia LH, Newman N, Rivard CH: Light and scanning electron microscopy of human spinal ligamentum flavum. A preliminary study. Spine 15:262-268, 1990

28. Chan LF, Lui CC, Cheng MH, Lin WJ: Ganglion cyst in the ligamentum flavum of the cervico-thoracic junction. J Formos Med
Assoc 95:490-492, 1996

29. Vernet O, Frankhauser H, Schnyder P, et al.: Cyst of the ligamentum flavum: Report of six cases. Neurosurgery 29:277-283, 1991

30. Terada H, Yokoyama Y, Kamata N, Hozumi T, Kondo T: Cyst of the ligamentum flavum. Neuroradiology 43:49-51, 2001

31. Wildi LM, Kurrer MO, Benini A, Weishaupt D, Michel BA, Buhlmann P: Pseudocystic degeneration of the lumbar ligamentum flavum. A little known entity. J Spinal Disord Tech 17:395340, 2004

32. Takano Y, Homma T, Okumura H, Takahashi HE: Ganglion cyst occurring in the ligamentum flavum of the cervical spine. A case report. Spine 17:1532-1533, 1992

33. Asamoto S, Jimbo H, Funkui Y, Doi H, Sakgawa H, Ida M, Takahashi M, Shiraishi N: Cyst of the ligamentum flavum-Case report. Neurol Med Chir (Tokyo) 45(12):653-656, 2005

34. KIM H, Singh R, Adsul N, et al.: Full endoscopic treatment of unusual spontaneous degenerative epidural cyst: A case report. Surgical Neurology International 10:58, 2019 